\title{
Tıp Fakültesi Öğrencilerinin Kahvaltı Yapma Alışkanlıkları ile Beden Kütle İndeksi Arasındaki İlişkinin Değerlendirilmesi Üzerine Bir Çalışma
}

\author{
A Study on the Evaluation of Relationship Between BreakfasEating Habits of Grade Students of \\ Medical Faculty and Body Mass Index
}

Yasemin Durduran¹, Ayşe Sağdıç², Lütfi Saltuk Demir ${ }^{3}$, Mehmet Uyar ${ }^{4}$, Mehtap Yücel ${ }^{5}$

Geliş tarihi/Received: 27.10.2020 • Kabul tarihi/Accepted: 24.02.2021

\section{ÖZET}

Amaç: Bu çalışmada, tıp fakültesi öğrencilerinin kahvaltı alışkanlıklarının ve ilişkili faktörlerin araştırılması hedeflenmiştir.

Bireyler ve Yöntem: Kesitsel türdeki bu çalışma, Necmettin Erbakan Üniversitesi Tıp Fakültesi'nde yürütülmüştür. Etik ve yazılı izinlerin alınmasının ardından çalışmanın verileri Kasım - Aralık 2015 tarihlerinde toplanmıştır. Araştırma için, çalışmacılar tarafından 29 sorudan oluşan, katılımcıların sosyodemografik özelliklerini, beslenme özelliklerini sorgulayan bir veri toplama formu geliştirilmiştir. Katılımcıların boy uzunluğu ve vücut ağırlıkları ölçülmüş, beden kütle indeksleri hesaplanmıştır. Sayısal değişkenlerin istatistiksel analizi Mann-Whitney U testi ile, kategorik veriler arasındaki ilişkiler kikare testi ile değerlendirilmiştir. İstatistiksel anlamlılık için $\mathrm{p}<0.05$ olarak kabul edilmiştir. Veri girişi ve analizi için SPSS 15.0 paket programı kullanılmıştır.

Bulgular: Bu çalışmaya, \%56.3’ü (n=198) 1. sınıfta, \%43.8’i $(n=154)$ 6.sınıfta eğitim gören 352 tıp fakültesi öğrencisi dâhil edilmiştir. Katılımcıların \%8.0'i zayıf, \%71.3'ü normal kilolu, \%18.2'si fazla kilolu, \%2.6’sı obez olarak saptanmıştır. Kahvaltı yapma sıklığı ile cinsiyet ve sınıflar arasında istatistiksel olarak anlamlı fark bulunmuştur ( $\mathrm{p}=0.027, \mathrm{p}<0.001)$. Kahvaltı yapılan yer, birlikte kahvaltı yapılan kişi ve kahvaltının başarıya etkisi olduğunu düşünme ile öğrencilerin sınıfları arasında istatistiksel olarak anlamlı fark bulunmuştur ( $\mathrm{p}<0.001, \mathrm{p}=0.009, \mathrm{p}=0.024)$.

Sonuç: Öğrencilere göre günün en önemli öğününün kahvaltı olduğu, en sık derse geç kalma nedeniyle öğün atlandığ ve atlanılan öğünün en fazla sabah kahvaltısı olduğu ortaya konmuştur. Öğrenciler sağlıklı beslenme ile ilgili bilgilerini, tutum ve davranışlara dönüştürme konusunda eğitilmeli ve en önemli öğün olan kahvaltı yapılarak güne başlamaları çeşitli etkinliklerle teşvik edilmelidir.

Anahtar kelimeler: Kahvaltı, öğrenci, tip fakültesi

1. Necmettin Erbakan Üniversitesi, Meram Tıp Fakültesi, Halk Sağlığı Anabilim Dalı, Meram, Konya, Türkiye - ๑ https://orcid.org/0000-0003-0455-0627

2. Necmettin Erbakan Üniversitesi, Meram Tıp Fakültesi, Halk Sağlığı Anabilim Dalı, Meram, Konya, Türkiye • ำ https://orcid.org/0000-0003-3360-5682

3. Necmettin Erbakan Üniversitesi, Meram Tıp Fakültesi, Halk Sağlığı Anabilim Dalı, Meram, Konya, Türkiye • •
4. Necmettin Erbakan Üniversitesi, Meram Tıp Fakültesi, Halk Sağllğı Anabilim Dall, Meram, Konya, Türkiye • ๑ https://orcid.org/0000-0002-3954-7471

5. İletişim/Correspondence: Necmettin Erbakan Üniversitesi, Meram Tıp Fakültesi, Halk Sağlığı Anabilim Dall, Meram, Konya, Türkiye E-posta: mhtpyucel@hotmail.com • @ https://orcid.org/0000-0001-6091-3205 


\section{ABSTRACT}

Aim: This study was aimed to investigate the breakfast habits of medical faculty students and related factors.

Subjects and Method: This cross-sectional study was conducted in Necmettin Erbakan University Faculty of Medicine. After obtaining ethical and written permissions, the data of the study were collected between November and December 2015. For the research, a data collection form was developed by the researchers, consisting of 29 questions on the sociodemographic characteristics and nutritional characteristics of the participants. Participants' height and body weight were measured and their body mass indexes were calculated. Mann-Whitney U test was used for the statistical analysis of numerical variables, and relationships between categorical data were evaluated by chi-square test. For statistical significance, $\mathrm{p}<0.05$ was accepted. SPSS 15.0 package program was used for data entry and analysis.

Results: In this study, 352 medical faculty students, 56.3\% ( $n=198)$ of whom were in the first year and $43.8 \%(n=154)$ in the 6th grade, were included. Only $8.0 \%$ of the participants were found to be underweight, $71.3 \%$ as normal weight, $18.2 \%$ overweight, $2.6 \%$ as obese. A statistically significant difference was found between the frequency of having breakfast and gender and classes $(p=0.027, p<0.001)$. A statistically significant difference was found between the classes of the students in terms of the place where breakfast was served, having breakfast together with a person and the thought that breakfast had an effect on success $(\mathrm{p}<0.001, \mathrm{p}=0.009, \mathrm{p}=0.024)$.

Conclusion: According to the students, it was revealed that the most important meal of the day is breakfast, breakfast is the most frequently skipped meal for not to be late to class and the most skipped meal is breakfast. Students should be educated about transforming their knowledge about healthy eating into attitudes and behaviors, and they should be encouraged to start the day with breakfast, the most important meal, with various activities.

Keywords: Breakfast, student, medical school

\section{GíRiş}

Bireyin ve toplumun sağlıklı yaşaması, ekonomik yönden gelişmesi, onu oluşturan bireylerin sağlıklı olmasına bağlıdır. Sağlığın temeli yeterli ve dengeli beslenmedir (1). Ergenlikten genç yetişkinliğe geçiş, sağlıklı beslenmenin desteklenmesi de dâhil olmak üzere sağlığı geliştirme stratejileri için özellikle önemli bir yaş dönemi olabilir. Çünkü bu dönemde birçok sağlık davranışı geliştirilir ve hayatın devamında geliştirilen bu davranışlar sürdürülür (2).

Gençlerin, üniversite eğitiminin başlaması ile birlikte alıştıkları aile ortamından ayrılmaları, dış etkilere daha açık hale gelmeleri ve kendi özgür seçimlerinin etkili olmasıyla beslenmelerinde yeni bir dönem başlamaktadır. Kendi başlarına almaları gereken temel kararların başında da beslenme ile ilgili seçimler gelmektedir. Bu dönem, ekonomik problemler, yeni kurulacak bir düzene uyum sağlama çabalarının getirdiği güçlükler, farklı yaş, cinsiyet ve kültürde olan pek çok insanla iletişim ve öğrenme süreci içine girilmesi bakımından önemlidir (2-4). Gençler bu dönemde sigara kullanma, spor yapma, diyet yapma, aşırı yeme, düzensiz beslenme, alkol kullanma gibi farklı sağlık davranışları sergileyebilir. $\mathrm{Bu}$ davranışlar üniversite öğrencilerinin beslenme alışkanlıklarını değiştirebilmektedir $(4,5)$.

Beslenme alışkanlıkları, insan sağlığının en önemli ve değiştirilebilir yaşam biçimi belirleyicisidir (2). Hem yetersiz beslenme, hem de aşırı beslenme ölümlerin ve hastalıkların oluşumunda önemli rol oynamaktadır. Özellikle yanlış beslenme alışkanlıklarından kaynaklanan çok sayıda hastalığın olması ve bunların beslenme alışkanlıkları değiştirilerek engellenebilmesi, çalışmaların bu yöne kaymasına sebep olmuştur. Bu nedenle beslenme durumunun saptanması bireyin ve toplumun sağlığının geliştirilmesinin temel taşıdır (6,7). Kahvaltı, beslenmede ilk ve en önemli öğün olarak yerini almaktadır. Yeni bir güne başlarken yeterli 
miktarda ve doğru bileşenlerle yapılan kahvaltı, öğrencilerin öğrenme performansında, günün verimli geçirilmesinde büyük rol oynamaktadır (8).

Düzenli kahvaltı yapma ile beden kütle indeks (BKI) arasında negatif ilişki olduğunu gösteren çalışmalar bulunmaktadır. Kesitsel bir çalışmada kahvaltıyı atlayan çocuklarda ve ergenlerde obezite riski, düzenli kahvaltı yapanlara göre $\% 43$ daha fazla bulunmuştur. Yine 2018 yılında 1733 ilkokul öğrencisiyle gerçekleştirilen bir çalışmada kahvaltı öğününü atlayan çocukların BKi’inde artan değişiklikler olduğu bildirilmiştir (9-10).

Üniversite öğrencilerinin doğru beslenme alışkanlıklarına sahip olması hem kendi sağlığı hem de toplum sağlığı açısından önemlidir. Değişen beslenme alışkanlıkları öğrencilerin fiziksel ve zihinsel durumlarını, eğitim performanslarını etkilemektedir (11). Bu sebeplerle üniversite öğrencilerinin beslenme alışkanlıklarının ve özellikle kahvaltı alışkınlıklarının saptanması ve sorunlar ile ilgili uygun çözümlerin oluşturulması büyük önem taşımaktadır. Bu çalışma tıp fakültesinde öğrenim gören birinci ve altıncı sınıf öğrencilerinin kahvaltı yapma alışkanlığının, kahvaltı yapma alışkanlıklarını etkileyen faktörlerin belirlenmesini ve BKİ ile ilişkisini değerlendirmeyi amaçlamaktadır.

\section{GEREÇ VE YÖNTEM}

Araştırma kesitsel tipte olup, 2015 yılı KasımAralık aylarında Necmettin Erbakan Üniversitesi Meram Tıp Fakültesi'nde yapılmıştır. Çalışmanın evrenini, Necmettin Erbakan Üniversitesi Meram Tıp Fakültesi’nde 2014-2015 öğretim yılında öğrenim gören birinci sınıftan 230, altıncı sinıftan 186 öğrenci oluşturmaktadır. Örneklem belirlenmeyip, her iki sınıfta öğrenim gören ve çalışmaya katılmaya gönüllü öğrencilere ulaşılması hedeflenmiştir. Her iki sınıfta öğrenim gören toplam 416 öğrencinin \%84'üne ( $n=352)$ ulaşılmıştır. Çalışma öncesinde Tıp Fakültesi Dekanlığından yazılı izin ve Necmettin Erbakan Üniversitesi Meram Tıp Fakültesi İlaç ve Tıbbi Cihaz Dışı Araştırmalar Etik Kurul'undan onay alınmıştır (Tarih: 18.12.2015 Sayl: 2015/383).
Araştırma için çalışmacılar tarafindan literatür desteğiyle 29 soru ve 3 bölümden oluşan bir veri toplama formu geliştirilmiştir. Formun 9 sorudan oluşan ilk bölümü sosyodemografik özellikleri, 11 sorudan oluşan ikinci bölümü beslenme özelliklerini, 9 sorudan oluşan son bölümü ise katılımcıların kahvaltı özelliklerini sorgulamaktadır. Veri toplama formunun ön denemesi 10 öğrenci üzerinde yapılmış olup, ön denemeye katılanlar araştırma kapsamına dâhil edilmemiştir. Ön denemesi yapıldıktan sonra son şekli verilen veri toplama formu, sözlü onam alınan katılımcılara yüz yüze görüşme yöntemiyle uygulanmış ve her bir form ortalama 10 dakikada doldurulmuştur. Veri toplama formunu eksiksiz dolduran katılımcıların boy uzunluğu ve vücut ağırlığı ölçümleri yapılmıştır. Öğrencilerin boy ölçümü Tanita marka stadiometre ile ayakkabıları çıkarılarak topukları birleşik, öğrenci dik dururken ve başının düz durması sağlanarak yapılmıştır. Ağırlık ölçümleri ise ayakkabısız hafif giysilerle, $200 \mathrm{~kg}$ kapasiteli 100 grama hassas Tanita marka HD-366 model dijital yer baskülü yardımıyla çalışmacılar tarafından ölçülmüş ve veri toplama formlarına kaydedilmiştir (1).

Öğrencilerin obezite durumu Dünya Sağllk Örgütü'nün (DSÖ) obezite sinıflandırması esas alınarak değerlendirilmiştir. Buna göre BKİ değeri $<18.50 \mathrm{~kg} / \mathrm{m}^{2}$ olanlar zaylf, $18.50-24.99 \mathrm{~kg} / \mathrm{m}^{2}$ olanlar normal, $25.00-29.99 \mathrm{~kg} / \mathrm{m}^{2}$ olanlar fazla kilolu ve $>30.00$ $\mathrm{kg} / \mathrm{m}^{2}$ olanlar obez olarak kabul edilmiştir $(12,13)$.

\section{Verilerin İstatistiksel Değerlendirmesi}

Veri girişi ve analizi için SPSS for Windows version 15.0 (SPSS Inc. Chicago, IL, USA) paket programı kullanılmıştır. Analizler sırasında; sayısal verilerin özetlenmesinde aritmetik ortalama \pm standart sapma, ortanca (minimum-maksimum) değerleri, kategorik verilerin özetlenmesinde frekans dağılımları ve yüzdelikler kullanılmıştır. Normal dağılmayan sayısal değişkenlerin istatistiksel analizi için Mann-Whitney U testi kullanılmıştır. Kategorik veriler arasındaki ilişkiler ki-kare testi ile değerlendirilerek $\mathrm{p}<0.05$ istatistiksel olarak anlamlı kabul edilmiştir. 


\section{BULGULAR}

Araştırma kapsamına alınan 352 öğrencinin yaş ortalamaları $21.15 \pm 2.83$ yıldır. Katılımcıların \%56.3’ü ( $n=198)$ birinci sinif, \%43.8'i (n=154) altıncl sinuf öğrencisidir (Tablo 1).

Öğrencilerin aylık harcadıkları ortalama para miktarı 600 TL (60-2.500 TL), aylık beslenmeye harcadığı para miktarı ise 250 TL (20-1000 TL) olarak bulunmuştur. Katılımcıların \%14.2'si (n=50) her gün düzenli olarak vitamin/mineral desteği aldığını, \%44.6’sı (n=157) öğün atladığını, \%88.4’ü $(n=311)$ öğünler dışında atıştırma, \%57.1'i de (n=201) gece atıştırma alışkanlığı olduğunu belirtmiştir (Tabloda gösterilmemiştir).

Diyet uygulayan sekiz öğrencinin tamamı bu diyeti zayıflamak için uyguladığını bildirmiştir. Vitamin/ mineral desteği alan 50 öğrencinin \%61.2'si daha dinç

Tablo 1. Öğrencilerin sosyodemografik özellikleri

\begin{tabular}{lcc}
\hline Özellik & $\mathbf{n}$ & $\mathbf{\%}$ \\
\hline Sınıf & 198 & 56.2 \\
1. sınıf & 154 & 43.8 \\
6. sınıf & & \\
Cinsiyet & 193 & 54.8 \\
Kız & 159 & 45.2 \\
Erkek & & \\
Medeni Durum & 8 & 2.3 \\
Evli & 344 & 97.7 \\
Bekâr & & \\
Kaldığı Yer & 94 & 26.7 \\
Aile ile Birlikte & 83 & 23.6 \\
Arkadaşları ile Birlikte Evde & 41 & 11.6 \\
Tek Başına Evde & 33 & 9.4 \\
Devlet Yurdunda & 101 & 28.7 \\
Özel Yurtta & & \\
Kronik Hastalık & 21 & 6.0 \\
Var & 331 & 94.0 \\
Yok & & \\
Sosyal Güvence & 305 & 86.6 \\
Var & 47 & 13.4 \\
Yok & & \\
Sigara İçme Durumu & 24 & 6.8 \\
İçiyor & 328 & 93.2 \\
İcmiyor & & \\
\hline
\end{tabular}

ve zinde hissetmek için, \%28.6’sı hasta olduğu için, $\% 10.2$ 'si diğer nedenlerle vitamin ve mineral desteği aldığını belirtmiştir (Tabloda gösterilmemiştir).

Öğün atladığını söyleyen 157 katılımcının \%66.2'si sabah, \%27.4’ü öğle, \%6.4’ü akşam öğününü atladığını belirtmiştir. Günün en önemli öğünü olarak öğrencilerin \%63.4’ü sabah, \%21.3’ü akşam, \%14.5’ü ise öğle öğününü ifade etmişlerdir (Tablo 2).

Öğrencilerin \%35.2'si sağlıklı beslendiğini, \%33.8’i bazen sağlıklı beslendiğini ve \%31.0’ı sağlıklı beslenmediğini düşünmektedir. Öğrencilerin günlük öğün sayısı ortancası 4 (min:1, maks:8) olarak bulunmuştur. Öğrencilerin \%43.2'si her gün düzenli kahvaltı yaptığını bildirmiştir. Öğrencilerin kahvaltı alışkanlıklarına ait bilgiler Tablo 2'de sunulmuştur.

Kadın öğrencilerin düzenli kahvaltı yapma alışkanlığı erkeklerden $(p=0.027)$, birinci sinıf öğrencilerinin düzenli kahvaltı yapma sıklığı, altıncı sinıf öğrencilerden istatistiksel olarak önemli yüksek bulunmuştur ( $\mathrm{p}=0.001$, Tablo 3 ).

Kahvaltı yapılan yer sorgulandığında, altıncı sinıf öğrencilerinin birinci sinıf öğrencilerine oranla kahvaltıyı hastane kantininde daha fazla yaptıkları ve aradaki farkın istatistiksel olarak anlamlı olduğu görülmüştür $(\mathrm{p}<0.001)$. Öğrencilerin devam ettikleri sınıflara göre kahvaltıya ilişkin özellikleri Tablo 4'de sunulmuştur.

Öğrencilerin, BKİ’ne göre \%8.0'ının (n=28) zayıf, \%71.3’ünün $(\mathrm{n}=251)$ normal kilolu, \%18.2'sinin $(n=64)$ fazla kilolu, \%2.6'sının $(n=9)$ obez olduğu belirlenmiştir. Cinsiyete göre değerlendirildiğinde, erkek öğrencilerin \%66.7’sinin normal kilolu, \%33.3’ü fazla kilolu veya obez olduğu, kadın öğrencilerin \%14.5'inin zayıf, \%75.1'inin normal kilolu, \%10.4’ünün fazla kilolu veya obez olduğu görülmüştür. Öğün atlayan öğrencilerin \%21.7’si fazla kilolu/obez, öğün atlamayan öğrencilerin \%20.0'ı fazla kilolu/ obez olduğu ve BKİ ortancaları ile öğün atlama durumları arasında istatistiksel fark bulunmadığı 
Tablo 2. Öğrencilerin kahvaltı alışkanlıklarına ait bazı sorulara verdiği yanıtlar

\begin{tabular}{|c|c|c|}
\hline Özellik & $\mathbf{n}$ & $\%$ \\
\hline \multicolumn{3}{|l|}{ Kahvaltı yapma sıklığı $(n=352)$} \\
\hline Haftada 1-2 gün & 57 & 16.2 \\
\hline Haftada 3-4 gün & 67 & 19.0 \\
\hline Haftada 5-6 gün & 76 & 21.6 \\
\hline Her gün & 152 & 43.2 \\
\hline \multicolumn{3}{|l|}{ En çok kahvaltı yapılan yer $(n=349)$} \\
\hline Ev & 222 & 63.6 \\
\hline Okul kantini & 109 & 31.2 \\
\hline Hastane kantini & 18 & 5.2 \\
\hline \multicolumn{3}{|l|}{ Birlikte en çok kahvaltı yapılan kişi (n=269) } \\
\hline Tek başına & 79 & 29.4 \\
\hline Aile ile birlikte & 51 & 19.0 \\
\hline Arkadaşlarla birlikte & 123 & 45.7 \\
\hline Bazen aile, bazen arkadaşlarla & 16 & 5.9 \\
\hline \multicolumn{3}{|l|}{ Öğrencilere göre günün en önemli öğünü (n=352) } \\
\hline Sabah & 223 & 63.4 \\
\hline Öğle & 51 & 14.5 \\
\hline Akşam & 75 & 21.3 \\
\hline Hepsi & 3 & 0.9 \\
\hline \multicolumn{3}{|l|}{ Genellikle atlanılan öğün (n=157) } \\
\hline Sabah & 104 & 66.2 \\
\hline Öğle & 43 & 27.4 \\
\hline Akşam & 10 & 6.4 \\
\hline \multicolumn{3}{|l|}{ Düzenli kahvaltı yapmama nedeni $(n=200)$} \\
\hline Derse geç kaldığı için & 94 & 47.0 \\
\hline Kahvaltıya ayıracak vakti olmadığı için & 35 & 17.5 \\
\hline Hazırlayanı olmadığı için & 26 & 13.0 \\
\hline İştahı olmadığı için & 25 & 12.5 \\
\hline Diğer (kahvaltı alışkanlığı olmaması, açlık hissetmemesi vb.) & 20 & 10.0 \\
\hline \multicolumn{3}{|l|}{ Kahvaltı yapılmadığında görülen semptomlar (n=352)* } \\
\hline Açlık & 229 & 65.1 \\
\hline Halsizlik & 165 & 46.9 \\
\hline Dikkatte azalma & 128 & 36.4 \\
\hline Yorgunluk & 119 & 33.8 \\
\hline Baş ağrısı & 87 & 24.7 \\
\hline Diğer (Göz kararması, çarpıntı, üşüme vb.) & 73 & 20.8 \\
\hline \multicolumn{3}{|l|}{ Kahvaltı yapmamanın başarı üzerine etkisi (n=352) } \\
\hline Etkisi var & 222 & 63.0 \\
\hline Etkisi yok & 130 & 37.0 \\
\hline
\end{tabular}

*Katllimclar birden fazla semptom belirtmiştir.

görülmüştür ( $p=0.262$, tabloda gösterilmemiştir). Birinci ve altıncı sınıf öğrencilerinin cinsiyete göre
BKİ ortancaları arasında ise istatistiksel olarak önemli fark bulunmuştur ( $\mathrm{p}<0.001$, Tablo 5). 
Tablo 3. Öğrencilerin cinsiyet ve sınıflarına göre kahvaltı yapma sıklıkları

\begin{tabular}{|c|c|c|c|c|c|c|c|c|c|c|}
\hline & \multicolumn{2}{|c|}{ Haftada 1-2 gün } & \multicolumn{2}{|c|}{ Haftada 3-4 gün } & \multicolumn{2}{|c|}{ Haftada 5-6 gün } & \multicolumn{2}{|c|}{ Her gün } & \multirow{2}{*}{$\mathbf{x}^{2}$} & \multirow{2}{*}{$\mathbf{p}$} \\
\hline & $\mathbf{n}$ & $\%$ & $\mathbf{n}$ & $\%$ & $\mathbf{n}$ & $\%$ & $\mathbf{n}$ & $\%$ & & \\
\hline \multicolumn{11}{|c|}{ Cinsiyet } \\
\hline Kadın & 24 & 42.1 & 38 & 56.7 & 36 & 47.7 & 95 & $62.5^{*}$ & \multirow{2}{*}{9.142} & \multirow{2}{*}{0.027} \\
\hline Erkek & 33 & 57.9 & 29 & 43.3 & 40 & 52.6 & 57 & 37.5 & & \\
\hline \multicolumn{11}{|l|}{ Sinıf } \\
\hline 1. sinif & 22 & 38.6 & 28 & 41.8 & 42 & 55.3 & 106 & $69.7^{*}$ & \multirow{2}{*}{24.175} & \multirow{2}{*}{0.001} \\
\hline 6. sinif & 35 & 61.4 & 39 & 58.2 & 34 & 44.7 & 46 & 30.3 & & \\
\hline
\end{tabular}

*Farklllı̆a sebep olan gruba işaret etmektedir.

${ }^{* *}$ Ki-kare testi

Tablo 4. Öğrencilerin sınıflarına göre kahvaltıya ilişkin bazı özelliklerin değerlendirilmesi

\begin{tabular}{|c|c|c|c|c|c|c|}
\hline \multirow{2}{*}{ Değişkenler } & \multicolumn{2}{|c|}{ 1. sinif } & \multicolumn{2}{|c|}{ 6. sinif } & \multirow{2}{*}{$\mathrm{x}^{2 * *}$} & \multirow{2}{*}{$\mathbf{p}$} \\
\hline & $\mathbf{n}$ & $\%$ & $\mathbf{n}$ & $\%$ & & \\
\hline \multicolumn{7}{|l|}{ Öğün atlama durumu } \\
\hline Öğün atllyor & 85 & 54.1 & 72 & 49.5 & \multirow{2}{*}{0.513} & \multirow{2}{*}{0.474} \\
\hline Öğün atlamıyor & 113 & 57.9 & 82 & 42.1 & & \\
\hline \multicolumn{7}{|l|}{ En çok kahvaltı yapılan yer } \\
\hline $\mathrm{Ev}$ & 145 & 65.3 & 77 & 34.7 & \multirow{3}{*}{26.441} & \multirow{3}{*}{$<0.001$} \\
\hline Okul kantini & 47 & 43.1 & 62 & 56.9 & & \\
\hline Hastane kantini & 3 & 16.7 & 15 & $83.3^{*}$ & & \\
\hline \multicolumn{7}{|l|}{ Birlikte en çok kahvaltı yapılan kişi } \\
\hline Tek başına & 37 & 46.8 & 42 & 53.2 & \multirow{4}{*}{11.467} & \multirow{4}{*}{0.009} \\
\hline Ailemle & 34 & 66.7 & 17 & 33.3 & & \\
\hline Arkadaşlarımla & 86 & $69.9 *$ & 37 & 30.1 & & \\
\hline Bazen ailem, bazen arkadaşlarımla & 10 & 62.5 & 6 & 37.5 & & \\
\hline \multicolumn{7}{|c|}{ Kahvaltının başarıya etkisi olduğunu düşünme durumu } \\
\hline Düşünüyor & 134 & $60.4^{*}$ & 88 & 39.6 & \multirow{3}{*}{7.483} & \multirow{3}{*}{0.024} \\
\hline Düşünmüyor & 21 & 39.6 & 32 & 60.4 & & \\
\hline Fikri yok & 43 & 55.8 & 34 & 44.2 & & \\
\hline
\end{tabular}

*Farklllğa sebep olan gruba işaret etmektedir.

**Ki-kare testi

Öğrencilerin BKİ ile kahvaltı yapma sıklığı, kahvaltı yapılan yer, birlikte kahvaltı yapılan kişi arasındaki fark da incelenmiş, istatistiksel olarak anlamlı fark bulunamamıştır ( $\mathrm{p}>0.05)$.

\section{TARTIŞMA}

Kahvaltı öğününün, beyine enerji sağladığı ve öğrenme düzeyini etkilediği için genellikle günün en önemli öğünü olduğu, ayrıca günlük toplam enerji ve besin ögesi alımına önemli ölçüde katkıda bulunduğu bilinmektedir (11). Üniversite öğrencilerinin beslenme alışkanlıklarını inceleyen bir çalışmada, öğrencilerin \%45.8’inin sabah öğününü atladığı bildirilmiştir (11). Bu çalışmada, günün en önemli öğününün sabah öğünü olduğunu belirtenlerin oranı \%63.4 olmasına rağmen, en fazla atlanılan öğün \%66.2 oranında yine sabah öğünü olmuştur (Tablo 2). Üniversite öğrencilerinin öğün atlamaları ve BKİ arasındaki ilişkiyi inceleyen bir diğer çalışmada, öğün atlayan öğrencilerin \%17.2'sinin fazla kilolu, \%5.2'sinin de obez olduğu, öğrencilerin öğün atlama durumunun 
Tablo 5. Öğrencilerin devam ettikleri sinıflarda ve cinsiyetlerine göre BKİ ortanca ve min-maks değerleri

\begin{tabular}{|c|c|c|c|c|c|}
\hline \multirow{2}{*}{ Sinif } & \multirow{2}{*}{ Cinsiyet } & \multicolumn{2}{|c|}{ Beden Kütle İndeksi (kg/m²) } & \multirow{2}{*}{$\mathbf{z}^{*}$} & \multirow{2}{*}{$\mathbf{p}$} \\
\hline & & Ortanca & Min-Max & & \\
\hline \multirow{2}{*}{ 1. sinif } & Kadın & 21.0 & $16.6-31.6$ & \multirow{2}{*}{-5.366} & \multirow{2}{*}{$<0.001$} \\
\hline & Erkek & 22.9 & $18.5-32.8$ & & \\
\hline \multirow{2}{*}{ 6. sinif } & Kadın & 20.8 & $16.0-30.4$ & \multirow{2}{*}{-6.277} & \multirow{2}{*}{$<0.001$} \\
\hline & Erkek & 24.0 & $18.5-30.8$ & & \\
\hline
\end{tabular}

*Mann-Whitney U testi

BKİ sinıflamasına göre istatistiksel olarak ileri düzeyde anlamlı olduğu ( $p<0.01)$ bildirilmiştir (14). $\mathrm{Bu}$ çalışmada ise öğün atlayan öğrencilerin \%21.7’si fazla kilolu/obez, öğün atlamayan öğrencilerin \%20 .0’ı fazla kilolu/obez olarak bulunmuştur.

Öğrencilerin öğün atlama ve düzensiz beslenme nedenlerini araştıran çalışmalar incelendiğinde, Pakistan'da yapılan çalışmada vakit bulamama nedeni ile öğün atlama oranının tıp fakültesi öğrencilerinde \%52.3 olduğu görülmektedir (15). Aytekin (16) tarafından Ankara'da yapılan bir çalışmada, üniversite öğrencileri için öğün atlama nedeni olarak zaman sorunu ilk sirada yer alırken isteksizlik daha sonra gelmektedir. Sajwania et al. (15) yaptıkları çalışmada da öğrencilerin öğün atlama sebeplerini en fazla zaman bulamama olarak belirtmişlerdir. $\mathrm{Bu}$ çalışmanın sonuçları da mevcut çalışmaları desteklemektedir. Kahvaltı yapamama nedenleri olarak öğrencilerin yaklaşık yarısı derse geç kaldığını belirtirken, kahvaltı için vakit bulamama, iştahsızlık ve hazırlayan birinin olmaması diğer önemli nedenler olarak ön plana çlkmaktadır (Tablo 2). Öğrencilerin bu kaygıları nedeniyle kolay ulaşlabilen besinlerle öğünlerini geçirdiği düşünülmektedir.

Kahvaltı yapılmadığında görülen semptomların en başında açlık hissetmek, halsizlik, yorgunluk ve dikkatte azalma gelmektedir (Tablo 2). Önay (17) tarafından sağlık yüksekokulunda yapılan bir çalışmada da benzer sonuçlar bulunmuştur.

Beslenme alışkanlıkları ile ilgili Artvin'de paramedik öğrencileriyle yapılan bir çalışmada öğrencilerin \%33.3’ünün her gün düzenli kahvaltı yaptığı belirtilmiştir (18). Lübnan'da üniversite öğrencileri ile yapılan bir çalışmada da öğrencilerin 1/3 ünün düzenli kahvaltı yaptığı bulunmuştur (19). Bu çalışmada, öğrencilerin \%43.2'si her gün düzenli kahvaltı yaptığını belirtmişlerdir. Çalışmada, öğrencilerin kahvaltı yapma sıklıkları değerlendirildiğinde, kadınların erkeklere göre, birinci sinıfta okuyan öğrencilerin altıncı sinıfta okuyan öğrencilere göre her gün düzenli kahvaltı yapma oranı istatistiksel olarak önemli $(p<0.05)$ bulunmuştur. Birinci sınıftaki öğrencilerin yaklaşık dörtte üçü her gün düzenli kahvaltı yaparken, altıncı sinıfta bu sıklık \%30.0’a düşmektedir (Tablo 3). Altıncı sınıf öğrencilerinde, stajların daha yoğun geçmesinin, nöbet tutulan bir çalışma sistemine geçiliyor olmasının sonuçları etkilediği düşünülmektedir. Ayrıca cinsiyetler arası farklılıkta kadınların, kahvaltıya daha fazla önem verdikleri, sağlıklı yeme davranışları konusunda daha bilgili oldukları ifade edilebilir. Yapılan bir çalışma öğrencilerin \%70’inin kahvaltıyı evde, \%30’unun ise okulda yaptığını bildirmiştir (14). Başka bir çalışmada ise fazla kilolu ve obez olan öğrencilerin evde kahvaltı yapma oranının düşük olduğu bildirilmiştir (sırasıyla \%36.4, \%20.0). Yine aynı çalışmada ailesiyle birlikte yaşayanlarda obezite oranı \%20.0 iken, tek başına veya arkadaşlarıyla evde kalanlarda \%60.0 olarak bulunmuştur (20). Bu çalışmada, "birlikte en çok kahvaltı yapılan kişi” sorgulandığında "ailemle" veya "arkadaşlarımla" cevabı veren birinci sınıf öğrencilerinin altıncı sınıf öğrencilerinden yüksek olduğu ve aradaki farkın istatistiksel olarak önemli olduğu görülmüştür. Evde kahvaltı yapma oranları da birinci sınıf öğrencilerinde daha yüksek ve istatistiksel olarak önemli bulunmuştur (Tablo 4). Düzenli ev hayatı olan ve birbirini destekleyen 
bireylerle birlikte yaşamanın kahvaltıya etkisi olduğu düşünülmüştür. Ayrıca altıncı sinıf tıp fakültesi öğrencilerinin meslek hayatına atılmadaki son adım olan intörnlük döneminde yoğun çalışma temposu içinde olması, nöbet hayatının başlaması kahvaltı ve beslenme düzenlerini değiştirmiş olabilir.

Öğrencilerin sınıflarıkendiiçinde değerlendirildiğinde her iki sınıfta okuyan öğrenciler için BKİ kategorileri ile cinsiyet arasinda istatistiksel olarak anlamlı fark bulunmuştur (Tablo 5). Bu fark kadınların daha fazla oranda zayıf veya normal kilolu olmasindan kaynaklanmaktadır. Aynı ilde farklı fakültelerde yapılan bir çalışmada da BKİ kategorisine göre benzer oranlar elde edilmiştir. Çalışmada cinsiyetler arasında kadınların daha zayıf olmasından kaynaklanan anlamlı bir fark olduğu bildirilmiştir (11). Bu bulgu kadınların fiziksel görünüşlerine daha fazla önem vermesinden, sağlıklı yeme davranışlarıyla erkeklere göre daha ilgili olmalarından kaynaklanabilir.

Yapılan bir çalışmada kahvaltıyı atlayanlar arasında kızların \%40.7'sinin ve erkeklerin \%54.7'sinin fazla kilolu veya obez olduğu, hem Amerika Birleşik Devletleri'nde hem de Yunanistan'da obezite prevalansının, kahvaltı öğününü atlayan çocuklar ve ergenler arasında önemli ölçüde yüksek olduğu belirtilmiştir (21). Bu çalışmada kahvaltı yapma sıklıkları ile öğrencilerin BKİ kıyaslamasında istatistiksel olarak anlamlı fark bulunmamıştır. Çalışmanın sağlıkla ilgili eğitim gören öğrenciler üzerinde gerçekleştirilmesinin, kahvaltının önemini bilen ve düzenli beslenme alışkanlıkları hakkında bilgi sahibi öğrencilerin çoğunlukta olması bu sonuçlara sebep olabilir.

Sonuç olarak, üniversite öğrencilerinin kahvaltı alışkanlıkları ile BKİ arasındaki ilişkinin değerlendirildiği bu çalışmada; öğrencilerin yaklaşık yarısının düzenli kahvaltı yaptığı, önemli fark oluşturmamakla birlikte öğrencilerin kahvaltı yapma sıklıkları ile BKİ'nin kıyaslanmasında her gün düzenli kahvaltı yapan öğrencilerin diğer gruplara oranla daha zayıf veya normal kilolu olduğu görülmüştür. Cinsiyetler ve sinıflar arasında kahvaltı yapma sıklığı açısından fark olduğu, en fazla önem verilen ancak çoğu öğrencinin zaman bulamama nedeniyle en çok atlanan öğünün sabah kahvaltısı olduğu ortaya konmuştur. Katılımcıların yaklaşı üçte birinin sağlıklı beslendiğini düşündüğü ve yalnız yaşayanlarda kahvaltı yapma oranının düştüğü gözlenmiştir. Öğrenciler hem kendi sağlıkları hem de hazırlandıkları meslek açısından gelecekte toplum sağlığına etki edecek bireyler olarak özel önem verilmesi gereken bir grubu teşkil etmektedir. $\mathrm{Bu}$ nedenle üniversitelerde yeterli ve dengeli beslenmenin, fiziksel aktivitenin önemi konusunda konferanslar ve bilimsel etkinlikler yapılmalıdır. Böylece yeni bir sağlıklı yaşam bilinci ve beslenme kültürü oluşturulmalıdır.

Bu çalışma Türkiye'nin belirli bir bölgesinde, belirli okul ve belirli öğrenciler üzerinde yapıldığından sonuçlar genellenemez. Bu durum araştırmanın bir kısıtlılığıdır. Bu konuyla ilgili daha kapsamlı araştırmaların yapılması önerilmektedir.

Yazarlık katkısı - Author contributions: Çalışmanın tasarımi: $Y D, A S, L S D$; Çalışma verilerinin elde edilmesi: $A S$, $M Y$; Verilerin analiz edilmesi: $Y D, M U, M Y ;$ Makale taslağının oluşturulması: YD, LSD, MU, MY; Iç̧erik için eleştirel gözden geçirme: $Y D, A S, L S D, M U, M Y$; Yayınlanacak versiyonun son onayl: $Y D, L S D, M U, M Y$ - Study design: $Y D, A S, L S D$; Data collection: AS, MY; Data analysis: YD, MU, MY; Draft preparation: YD, LSD, MU, MY; Critical review for content: $Y D, A S, L S D, M U, M Y$; Final approval of the version to be published: $Y D, L S D, M U, M Y$.

Etik Kurul Onayı - Ethics approval: Araştırma için Necmettin Erbakan Üniversitesi Meram Tip Fakültesi İlaç ve Tıbbi Cihaz Dışı Etik Kurulu'ndan (18.12.2015-2015/383) etik onay alınmıştır. - Ethical approval was obtained for the study from the Ethics Committee of Necmettin Erbakan University, Meram Faculty of Medicine, Non-Pharmaceutical and Medical Devices (18.12.2015-2015/383).

Çıkar çatışması - Conflict of interest: Yazarlar çıkar çatışması olmadığını beyan ederler. - The authors declare that they have no conflict of interest. 


\section{KAYNAKLAR}

1. Pekcan G. Beslenme durumunun saptanması. 2. Baskı. Ankara: Sağlık Bakanlığı; 2008.1-52.

2. Hilger J, Loerbroks A, Diehl K. Eating behaviour of university students in Germany: Dietary intake, barriers to healthy eating and changes in eating behaviour since the time of matriculation. Appetite. 2017;109:100-107.

3. Baldini M, Pasqui F, Bordoni A, Maranesi M. Is the mediterranean lifestyle still a reality? Evaluation of food consumption and energy expenditure in Italian and Spanish university students. Public Health Nutr. 2009;12:148-55.

4. Kowalkowska J, Wadolowska L, Wuenstel JW, Słowinska MA, Niedzwiedzka E. Socioeconomic status and overweight prevalence in Polish adolescents: The impact of single factors and a complex index of socioeconomic status in respect to age and sex. Iran J Public Health. 2014;43:913-25.

5. Deliens T, Clarys P, De Bourdeaudhuij I, Deforche B. Determinants of eating behaviour in university students: A qualitative study using focus group discussions. BMC Public Health. 2014;14(53):1-12.

6. Achinihu G. Nutritional status of university students in South-Eastern states of Nigeria. Journal of Research in National Development. 2009;7(2):25-32.

7. Ganasegeran K, Al-Dubai SA, Qureshi AM, Al-Abed AAA, Rizal AM, Aljunid SM. Social and psychological factors affecting eating habits among university students in a Malaysian medical school: A cross-sectional study. Nutr J. 2012;11:48-55.

8. Ersoy N, Ayaz A. Üniversite öğrencilerinin kahvaltı yapma alışkanlıklarının saptanması. Beslenme ve Diyet Dergisi. 2012;40(3):211-7.

9. Traub M, Lauer R, Kesztyüs T, Wartha O, Steinacker JM, Kesztyüs D. Skipping breakfast, overconsumption of soft drinks and screen media: Longitudinal analysis of the combined influence on weight development in primary school children. BMC Public Health. 2018;18(1): 363-73.
10. Ardeshirlarijani E, Namazi N, Jabbari M, Zeinali M, Gerami H, Jalili RB, et al. The link between breakfast skipping and overweigh/obesity in children and adolescents: A meta-analysis of observational studies. J Diabetes Metab Disord. 2019;18:657-64.

11. Yücel K. Evaluation of university students' nutritional knowledge attitudes and behaviors. J Basic Clin Health Sci. 2020;4:133-9.

12. Word Health Organization, Obesity and overweight. Erişim: https://www.who.int/news-room/fact-sheets/ detail/obesity-and-overweight Erişim tarihi: 08 Eylül 2020.

13. T.C. Sağlık Bakanlığı Halk Sağlığı Genel Müdürlüğü, Sağlıklı Beslenme ve Hareketli Hayat Dairesi Başkanlığı. Erişim: https://hsgm.saglik.gov.tr/tr/obezite/obezitenasil-saptanir.html Erişim tarihi: 08 Ağustos 2020.

14. Akça SÖ, Selen F. The effect of skipping meals and daily activities of university students regarding the body mass index (BMI). TAF Preventive Medicine Bulletin. 2015;14(5):394-400.

15. Sajwani RA, Shoukat S, Raza R, Shiekh MM, Rashid Q, Siddique MS, et al. Knowledge and practice of healthy lifestyle and dietary habits in medical and nonmedical students of Karachi, Pakistan. J Pak Med Assoc. 2009;59(9):650-5.

16. Aytekin F. Üniversite öğrencilerinin beslenme durumları üzerine bir araştırma. Gıda Dergisi. 2000;25(2):121-6.

17. Önay D. Üniversite öğrencilerinin kahvaltı alışkanlıklarının değerlendirilmesi: Akşehir Sağlık Yüksekokulu Örneği. Gazi University, Periodical of the Educational Faculty for Industrial Arts. 2011;27:95-106.

18. Küçük U. Paramedik öğrencilerinin beslenme durumları ve etkileyen faktörler. Adnan Menderes Üniversitesi Sağlık Bilimleri Fakültesi Dergisi. 2019;3(1):1-10.

19. Yahia N, Achkar A, Abdallah A, Rizk S. Eating habits and obesity among Lebanese university students. Nutr J. 2008;32(7):1-6.

20. Özütürker S, Özer BK. Erzincan üniversitesi öğrencilerinin beslenme alışkanlıkları ve antropometrik özelliklerinin değerlendirilmesi. Erzincan Üniversitesi Sosyal Bilimler Enstitüsü Dergisi. 2016;9(2):63-74.

21. Gotthelf SJ, Tempestti CP. Breakfast, nutritional status, and socioeconomic outcome measures among primary school students from the City of Salta: A cross-sectional study. Arch Argent Pediatr. 2017;115:424-31. 